LA-UR $98-3188$

Approoed for public release; distribution is unlimited.

PERFORMANCE AND TEST RESULTS OF A REGULATED MAGNETRON PULSER

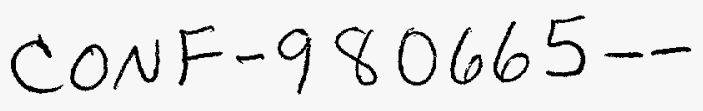

AUTHOR(S):

C.R. Rose, LANSCE-12

D.S. Warren, LANSCE-8

International Power Modulator Symposium, 22 June - 25 June, 1998

Rancho Mirage CA

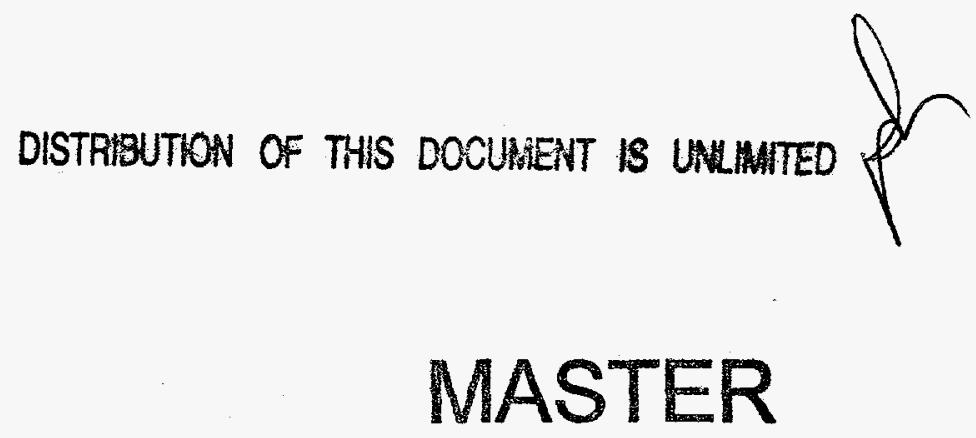

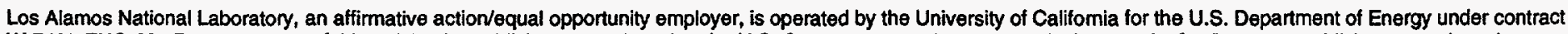

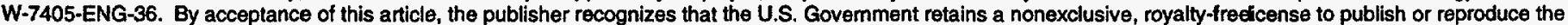

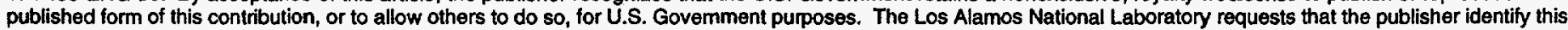

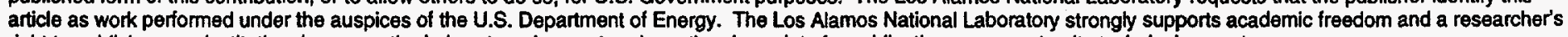
right to publish; as an institution, however, the Laboratory does not endorse the viewpoint of a publication or guarantee its technical correctness. 


\section{DISCLAIMER}

This report was prepared as an account of work sponsored by an agency of the United States Government. Neither the United States Government oor any agency thereof, nor any of their empioyees, makes any warranty, express or implied, or assumes any legal liability or responsibility for the accuracy, coropieteness, of usefulness of any information, apparatus, product, or process diselosed, or represents that its use would not infringe privately owned rights. Reference berein to any speciric commercial product, process, or service by trade name, trademarte, inanufacturer, or otherwise does not aecessarily constitute or impiy its exdorsement, recom. mendation, of favoring by the United States Government or any agency thereof. The views and opinions of authors expressed herein do not necessarily state or reflect those of the United States Governmeat or any agency thereof. 


\section{DISCLAIMER}

Portions of this document may be illegible in electronic image products. Images are produced from the best available original document. 


\title{
Performance and Test Results of a Regulated Magnetron Pulser ${ }^{\circ}$
}

\author{
Chris R. Rose and David S. Warren \\ Los Alamos National Laboratory \\ PO Box 1663 M/S H805, Los Alamos, NM 87545
}

\begin{abstract}
This paper describes the test results and performance of a $5.0-\mathrm{kV}, 750-\mathrm{mA}$, regulated current pulser used to drive an Hitachi model $2 \mathrm{M} 130$ 2,425-MHz magnetron. The magnetron is used to modulate the plasma in a particle accelerator injector. In this application, precise and stable if power is crucial to extract a stable and accurate particle beam. A $10-\mathrm{kV}$ high-voltage triode vacuum tube with active feedback is used to control the magnetron current and output if power. The pulse width may be varied from as little as ten microseconds to continuous duty by varying the width of a supplied gate pulse. The output current level can be programmed between 10 and $750 \mathrm{~mA}$. Current regulation and accuracy are better than $1 \%$. The paper will discuss the overall performance of the pulser and magnetron including anode current and if power waveforms, linearity compliance, and vacuum tube performance.
\end{abstract}

\section{INTRODUCTION}

The Accelerator Production of Tritium (APT) project at Los Alamos is developing a Low-Energy Demonstration Accelerator (LEDA) which uses a magnetron rf source in its injector. The amplitude of the injector output current is dependent on the magnetron rf-power level which depends directly on the magnetron anode current. To generate stable and precise injector current, the injector if source amplitude must be precisely controlled by its current. Thus the stability and accuracy of the magnetron current directly affects the accuracy of the injector current. This paper describes some of the performance results of the pulsed and cw magnetron current regulator designed for and now being used to support the LEDA project [1].
As a general overview, a simplified schematic of the pulser and magnetron is shown below in figure 1.

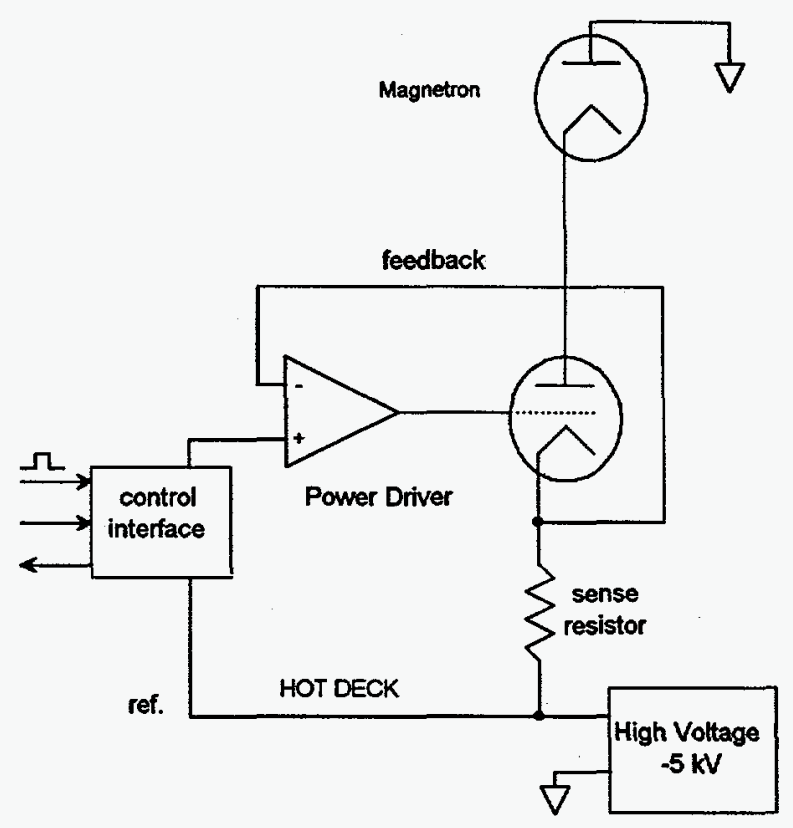

Figure 1. Simplified schematic of the pulser and magnetron. Not shown are the filament circuits.

Because of the high-voltage deck, control and instrumentation signals are applied via fiber optic circuits. The control interface accepts a GATE signal which determines the pulse width, a LEVEL signal used to program the current level, and sends back a monitor signal for triode cathode current. The power driver controls the triode grid voltage and receives a feedback signal from the cathode resistor circuit. The circuit is accurate except for whatever leakage current exists on the grid circuit. For monitoring purposes, the grid current is subtracted from the cathode current. Under normal operations, that is with specified triode anode to

\footnotetext{
-Work supported by the US Department of Energy.
} 
cathode voltage, the grid current is negligible and is not part of the real-time control loop.

\section{TEST RESULTS}

Several tests were performed on the pulser both into a resistive load and into the actual magnetron. The pertinent waveforms are shown below in figure 2.

\section{CONCLUSIONS}

Shortly into the magnetron and magnetron-pulser testing cycle, it was found that at the desired magnetron if power level, the magnetron exhibited excessive spurious sidelobe if components which interfered with proper injector operation [2]. Operating above or below this

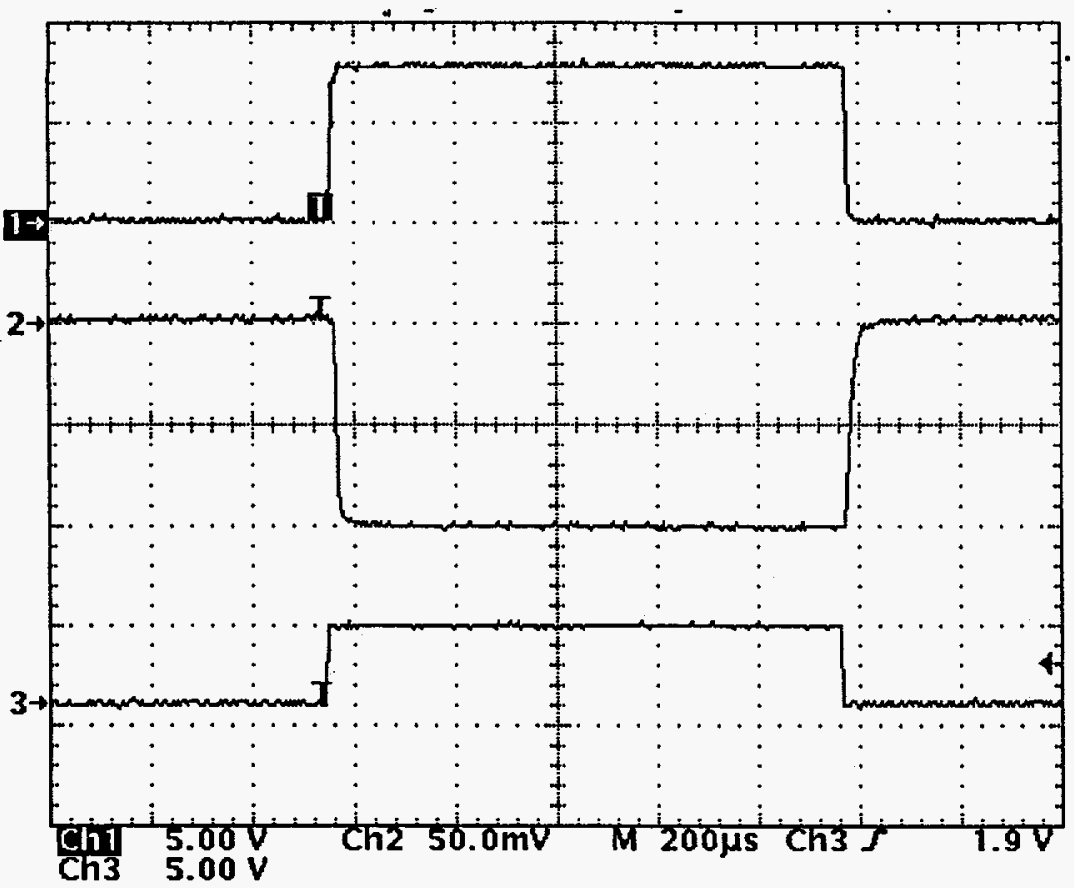

Figure 2. Tr 1-magnetron current (50mA/V), Tr 2-detected rf power from the magnetron $(100 \mathrm{~W} / \mathrm{V})$, and $\operatorname{Tr} 3-$ GATE pulse. band, the rf output spectrum was found to be much cleaner. As a result, the magnetron pulser was slightly altered to provide up to 750-mA drive for the magnetron which pushed it into an operating range with cleaner if which was then attenuated to the required level. The change to $750 \mathrm{~mA}$ was readily accomplished by changing the cathode resistor in figure 1 to $10 \Omega$ from $20 \Omega$ and properly scaling the input LEVEL signal. This increased current drive has stressed the power supply, and is in the process of having additional capacitance installed so that it can support longer pulse widths more easily.

As shown above, the magnetron current is at 400 mA for a detected if output power from the magnetron of about $700 \mathrm{~W}$. The risetime of the current pulse is about $4 \mu \mathrm{s}$ and its fall time is about $6 \mu$ s. The if pulse, which is the objective, has a risetime of about $4 \mu \mathrm{s}$ and a falltime of about 10 $\mu s$. These numbers are slower than those predicted by the circuit models of less than $1 \mu$ s but seem to be adequate [1].

The grid current was measured at several triode anode-current and anode-to-cathode voltage levels and matched the data sheet very closely confirming the assumption of negligible amounts of grid current leakage if operated within specifications.

\section{REFERENCES}

[1] Rose, C. R., "A Regulated Magnetron Pulser," to be published in these proceedings. [2] Zaugg, T., " ," published somewhere.... 